\title{
Psicossomática, Gestação e Diabetes: Um Estudo de Caso
}

\author{
Psychosomatic Disorders, Pregnancy \\ And Diabetes Mellitus: \\ A Case Study
}

Psicosomática, Gestación Y Diabetes: Un Estudio De Caso

Roselaine Fernanda Barbosa

Prefeitura Municipal de

Campo Limpo

Cláudia Aparecida

Marchetti Duarte

Faculdade Paulista de

Jaguariúna

Laise Potério dos Santos

Universidade de

Campinas

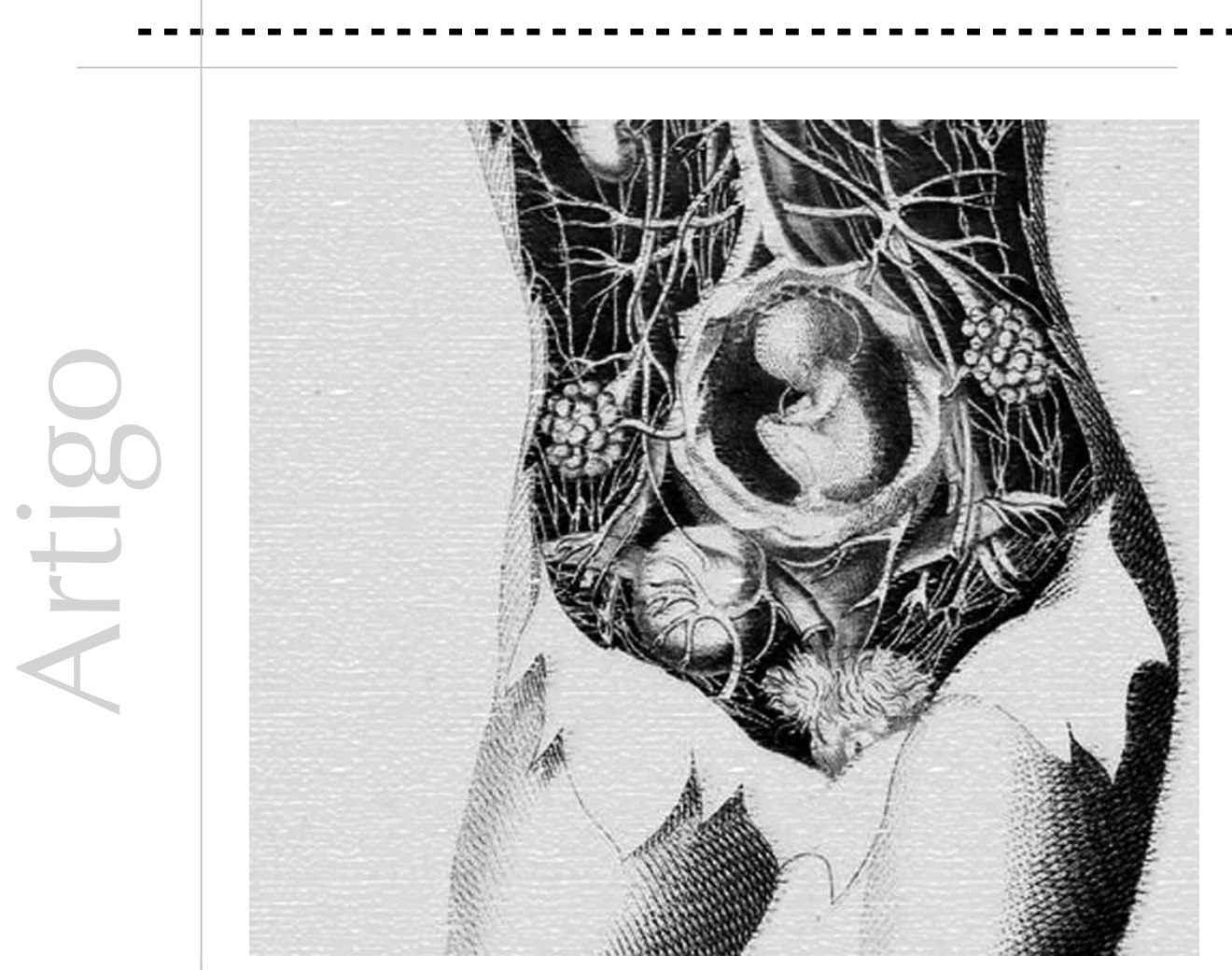


Resumo: Este trabalho apresenta o estudo de caso de uma paciente gestante portadora de diabetes melito, cujo acompanhamento psicológico foi realizado em um hospital universitário público do interior do Estado de São Paulo, referência em atendimento de alta complexidade no que se refere à saúde maternoinfantil. Os atendimentos ocorreram na instituição nas situações de consulta de pré-natal da paciente, e totalizaram cinco sessões. A técnica de atendimento psicológico consistiu na psicoterapia breve de orientação psicanalítica. São apresentados as repercussões do diabetes na gestante, os aspectos psicológicos associados à gravidez, o trabalho do psicólogo dentro de uma instituição hospitalar e uma reflexão acerca do conteúdo psicossomático do diabetes. Com base nesses elementos, este estudo de caso buscou analisar os aspectos psicológicos da gestação associados aos traços de personalidade típicos do paciente diabético bem como fornecer uma visão acerca das possibilidades e das limitações vivenciadas na relação paciente-psicólogo dentro do contexto hospitalar.

Palavras-chave: Estudo de caso. Gravidez de alto risco. Psicologia hospitalar. Diabetes na gravidez. Distúrbios psicossomáticos.

\begin{abstract}
This research presents the case study of a pregnant patient with diabetes mellitus. The psychological attendance took place in a public university hospital in the countryside of São Paulo, which is reference in high-complexity attendance regarding mother-child health care. The psychological interventions took place in the institution during the pre-birth attendance received by the patient, summing up five sessions. The chosen technique was brief psychotherapy - psychoanalysis oriented. The diabetes repercussions on the pregnant patient, the psychological aspects regarding pregnancy, the psychological care given inside a hospital institution, and a reflection on the psychosomatic content of diabetes are presented here. Based on these elements, this research aimed at analyzing the psychological aspects of pregnancy in association with the typical personality traits of patients with diabetes, as well as it provided a point of view of the possibilities and limitations experienced in the patient/psychologist relationship inside a hospital context.
\end{abstract}

Keywords: Case study. High-risk pregnancy. Hospitals Psychological aspects. Diabetes in Preganancy. Psychosomatic disorders.

Resumen: Este trabajo presenta el estudio de caso de una paciente gestante portadora de diabetes melito, cuyo acompañamiento psicológico ha sido llevado a cabo en un hospital universitario público del interior del Estado de San Pablo, referencia en atendimiento de alta complejidad en lo que se refiere a la salud materno-infantil. Los atendimientos han ocurrido en la institución en las situaciones de consulta pre-natal de la paciente, y han totalizado cinco sesiones. La técnica de atendimiento psicológico ha consistido en la psicoterapia breve de orientación psicoanalítica. Son presentadas las repercusiones de la diabetes en la gestante, los aspectos psicológicos asociados al embarazo, el trabajo del psicólogo dentro de una institución hospitalaria y una reflexión acerca del contenido psicosomático de la diabetes. Con base en estos elementos, este estudio de caso ha tratado de analizar los aspectos psicológicos de la gestación asociados a las características de personalidad típicos del paciente diabético, así como facilitar una visión acerca de las posibilidades y de las limitaciones vivenciadas en la relación paciente-psicólogo dentro del contexto hospitalario.

Palabras clave: Estudio de caso. Embarazo de alto riesgo. Psicología hospitalaria. Diabetes en embarazo. Disturbios psicosomáticos.

\title{
Caracterização do diabetes melito e repercussões na gravidez
}

O diabetes melito é uma doença metabólica caracterizada pela hiperglicemia, ocasionada por uma deficiência na secreção e/ou na ação da insulina (Aquino, Pereira, Amaral, Parpinelli, \& Passini Jr., 2003; Gross, Silveiro, Camargo, Reichelt, \& Azevedo, 2002). A doença é caracterizada pela destruição das células beta, e usualmente leva à deficiência completa de insulina (Gross et al., 2002).
Os efeitos da hiperglicemia no organismo se manifestam por sintomas como poliúria (aumento de urina), polidipsia (sede excessiva), perda de peso, polifagia (fome excessiva) e visão turva. A hiperglicemia crônica pode comprometer o funcionamento de vários órgãos, especialmente olhos, rins, nervos, coração e vasos sanguíneos (Gross et al., 2002). 
A ambivalência afetiva é um dos sentimentos comuns da gestação; o atraso menstrual, por si só, provoca esse sentimento pela possibilidade de estar ou não grávida, assim como o desejo de ter um bebê ou não, sendo essa ambivalência presente em todo o período de gravidez (Bortoletti, 2007).
Algumas complicações obstétricas podem repercutir na gestante diabética, como hipertensão arterial, parto prematuro, hipoglicemia, cetoacidose, infecções de trato urinário e outras infecções, doença periodontal, parto por cesariana (Golbert \& Campos, 2008; Montenegro, Paccola, Faria, Sales, \& Montenegro, 2001), bem como préeclâmpsia e mesmo morte materna (Silva, Santos, \& Parada, 2004; Montenegro et al., 2001).

As complicações neonatais mais frequentemente observadas são: macrossomia, com consequente aumento de indicação de partos cesáreos, prematuridade, hipoglicemia, hiperbilirrubinemia, policitemia, icterícia, hipocalcemia, síndrome do desconforto respiratório e aumento de duas a três vezes no risco de malformações congênitas (Golbert \& Campos, 2008; Corrêa \& Gomes, 2004; Montenegro et al., 2001).

\section{Aspectos psicológicos da gravidez e trabalho do psicólogo hospitalar em obstetrícia}

Todo ser humano, ao longo da vida, passa por momentos de transformação. Entretanto, existem certas épocas em que essas modificações ocorrem de maneira muito mais intensa e rápida.

A gravidez constitui um desses momentos singulares na vida da mulher, e, por esse motivo, desencadeia várias alterações no comportamento feminino. A ambivalência afetiva é um dos sentimentos comuns da gestação; o atraso menstrual, por si só, provoca esse sentimento pela possibilidade de estar ou não grávida, assim como o desejo de ter um bebê ou não, sendo essa ambivalência presente em todo o período de gravidez (Bortoletti, 2007).
Winnicott (1982) verificou um estado que se desenvolve na mulher durante a gestação e após o parto, chamado de preocupação materna primária, que consiste em uma espécie de regressão adaptativa em que a mãe, por sua sensibilidade aumentada, se identifica com o bebê a ponto de excluir temporariamente outros interesses.

O fenômeno da regressão em geral é visto de forma negativa, entretanto, propicia à mulher a possibilidade de ter comportamentos e sentimentos infantilizados, fundamentais para o estabelecimento de uma sintonia entre mãe e bebê, desde que não ultrapasse esse limiar a ponto de tornar-se algo patológico (Bortoletti, 2007).

Uma das primeiras manifestações do primeiro trimestre é a hipersonia, em que a mulher sente mais necessidade de dormir do que normalmente. Para Maldonado (2002), esse fenômeno representa a preparação do organismo para enfrentar as tensões fisiológicas adicionais, aumentando a necessidade de repouso. O oposto, a insônia, também pode ocorrer, sendo, nesse caso, provável que represente conteúdos de angústia significativos que devem ser cuidados (Bortoletti, 2007).

As náuseas e vômitos são os sintomas mais comuns do início da gravidez. O conhecimento a respeito da etiologia do fenômeno aponta a influência de vários aspectos, endócrinos, hormonais, bem como psicológicos (Maldonado, 2002). É comum a interpretação de que esses sintomas são uma expressão da rejeição da gravidez. No caso da hiperemese gravídica, pode-se supor que seja uma manifestação de rejeição, mas também não se pode concluir que em todos os casos se trate desse sentimento (Bortoletti, 2007).

Os desejos e aversões podem ser relacionados a superstições ou a folclore, a tentativas de compensar deficiências nutritivas, a 
necessidades afetivas ou a embotamento do paladar e olfato. Por vezes, os desejos são interpretados como necessidade de chamar a atenção, porém, assim como no caso da hiperemese, é importante não generalizar (Bortoletti, 2007).

Outra modificação refere-se ao aumento do apetite, sendo essa indisciplina alimentar vista como um comportamento regressivo, pois, muitas vezes, o desejo da mulher está centrado em itens que agradam o paladar infantil (Bortoletti, 2007). O aumento do apetite pode atingir graus de extrema voracidade e aumento de peso, a ponto de ocasionar diversas complicações obstétricas (Maldonado, 2002).

A hipersensibilidade é outro fator que se destaca nas alterações do ciclo gravidicopuerperal (Bortoletti, 2007). Essas oscilações de humor, segundo Maldonado (2002), devem-se ao próprio esforço de adaptação a uma nova realidade de vida, que envolve novas tarefas, responsabilidades, aprendizagem e descobertas.

A vida sexual do casal durante a gestação também pode sofrer alterações (Bortoletti, 2007). Para Maldonado (2002), a maneira como a mulher sente as alterações do esquema corporal está intimamente relacionada com as alterações da sexualidade, com a atitude do homem em relação a essas modificações e como ela própria se situa diante da gravidez.

Como se vê, a gravidez representa para a mulher um momento de crise. Utilizamos o conceito de crise como um momento constituído de etapas marcantes no ciclo de vida e que podem promover tanto um crescimento pessoal quanto o surgimento de vulnerabilidades emocionais (Canavarro, 2001).

Se a gravidez também estiver associada a alguma patologia, torna-se de extrema importância a participação do profissional de
Psicologia como um facilitador na elaboração dos conflitos que a situação de crise implica. Nesse contexto, surge a figura do psicólogo hospitalar, profissional que, segundo Sebastiani (2007), deve ter características próprias, adequadas e específicas que interfiram diretamente tanto em sua inserção quanto em seu desempenho na instituição.

Para Simonetti, "Psicologia hospitalar é campo de entendimento e tratamento dos aspectos psicológicos em torno do adoecimento" (2004, p. 15).

Enquanto a Medicina tem como função a cura de doenças, a Psicologia hospitalar busca compreender a relação que o doente tem com seu sintoma, para poder reposicionar o sujeito face à sua doença (Simonetti, 2004).

Ainda segundo Simonetti, a Psicologia hospitalar tem origem na psicanálise e na psicossomática: "ao que parece, a Psicologia hospitalar, que nasceu da psicossomática e da psicanálise, vem atualmente ampliando seu campo conceitual e sua prática clínica, com isso criando uma identidade própria e diferente" (2004, p.17).

Entretanto, é sabido que o ambiente hospitalar tem como protagonista a figura do médico, já que é ele quem decide sobre técnicas, medicações, cura, internações e alta (Angerami-Camon, 2003). Nesse contexto, os demais profissionais da saúde se adequam aos procedimentos médicos para, posteriormente, integrar sua prática ao atendimento hospitalar (Fossi \& Guareschi, 2004).

Assim, a atuação do psicólogo hospitalar está diretamente determinada por limites institucionais, como regras, rotinas, condutas específicas, dinâmicas que devem ser respeitadas e seguidas e que extrapolam a relação paciente/terapeuta (Sebastiani, 2007). Além disso, o local de trabalho desmobiliza 
Chiozza (1987) afirma que tanto os transtornos histéricos como os afetos, as doenças orgânicas e os próprios órgãos representam uma fonte inconsciente. a segurança e a tranquilidade do consultório tradicional, visto que, no hospital, o psicólogo atende entre macas, nos leitos das enfermarias e muitas vezes em meio a outros procedimentos e rotinas hospitalares. Isso obriga o profissional a transpor os limites do consultório e a aprofundar contatos com os outros profissionais com os quais convive (Sebastiani, 2007).

O tempo é um elemento importante a ser considerado no contexto hospitalar. Por esse motivo, o psicólogo necessita utilizar-se de psicoterapia breve e/ou de emergência, de acordo com as necessidades emergenciais da situação de doença e hospitalização (Sebastiani, 2007).

Outro fator importante refere-se à situação de indicação versus opção ao tratamento psicológico no hospital. Na instituição, diferentemente do tratamento clínico tradicional, não é o paciente quem procura atendimento, mas este é oferecido pelo próprio psicólogo (Sebastiani, 2007). Para Moretto (2001), tal fato não constitui necessariamente um problema, pois oferecer apoio psicológico ao paciente não significa a inexistência de demanda para tal.

\section{Diabetes: uma doença psicossomática?}

O processo de somatização consiste, basicamente, na manifestação de conflitos e angústias por meio de sintomas corporais (Coelho \& Ávila, 2007). Nesse sentido, a psicossomática busca um entendimento da relação mentecorpo e dos processos de adoecimento (Capitão \& Carvalho, 2006; Ávila, 2004).

Existem diversas definições e correntes sobre o conceito de psicossomática. Entendemos o termo psicossomático como toda perturbação física resultante de um conteúdo psicológico que interfere na gênese da doença.
Segundo Mello (1994), toda doença humana é psicossomática, já que incide em um ser constituído de soma e psique, inseparáveis anatômica e funcionalmente.

Quando a dor psíquica e o conflito psíquico oriundos de uma fonte de estresse ultrapassam a capacidade habitual de tolerância, em vez de serem reconhecidos e elaborados, podem ser descarregados em manifestações somáticas, remetendo a uma falha na capacidade de simbolização e de elaboração mental. Desse modo, com certas dificuldades de enfrentar tensões, o adoecimento pode ser considerado uma tentativa de estabelecer um equilíbrio para o corpo, assim como o sintoma neurótico representa a saída para um conflito psíquico (Capitão \& Carvalho, 2006).

Para Ferraz (2007), as modalidades de sintoma definidas pelas defesas neuróticas, ligadas à formação de representações, de seu recalque e de seu ressurgimento sob formas simbólicas, vão dando lugar a manifestações somáticas, pré-simbólicas, brutas ou cruas. O corpo, mais do que a linguagem, seria o cenário onde essas formações se desenvolvem, dando origem às mais diversas formas de adoecimento psicossomático.

Chiozza (1987) afirma que tanto os transtornos histéricos como os afetos, as doenças orgânicas e os próprios órgãos representam uma fonte inconsciente. Assim, o adoecimento surge na tentativa de ocultar de si mesmo uma história cujo significado não pode suportar, sendo uma resposta simbólica que busca, inconscientemente, alterar o significado da história ou o seu desenlace.

Segundo Mello (1994), a ansiedade é uma das energias geradoras básicas dos sintomas psicossomáticos, e, exatamente por esse caráter inconsciente, busca a via da expressão corporal.

Santos (2003) define a ansiedade como uma angústia subjetiva, decorrente de mudanças 
significativas de vida, como consequência de acontecimentos estressantes. Esses acontecimentos inesperados são crises acidentais que podem interferir na estabilidade emocional do indivíduo.

Além da ansiedade, observa-se também que situações de perda podem favorecer a eclosão de várias enfermidades, destacando que, no caso, é dada importância à perda emocional vivenciada pelo indivíduo. A vulnerabilidade do ego à frustração parece ser a condição básica geradora, seja das neuroses, seja da predisposição psicológica do adoecer (Mello, 1994).

Segundo Zeljko (2000), toda necessidade existencial é também uma necessidade corpórea. Quando o bebê não é atendido na necessidade de formar a unidade psiquesoma, não é atendido em sua necessidade de ser, isso resulta sempre em uma doença não apenas psíquica, mas, ao mesmo tempo, psicossomática.

Observa-se que, nas patologias atuais, a relação com o objeto primário se caracteriza por vínculos breves, frágeis ou mesmo precocemente interrompidos. A vivência da triangulação não é suficientemente acentuada, não somente nos casos-limite mas também nos quadros heterogêneos que a eles se assemelham (Horn, 2007).

\section{Método}

\section{Apresentação do caso}

$\mathrm{Na}$ época do acompanhamento psicológico, Elaine (nome fictício) tinha 21 anos de idade, com diagnóstico de diabetes melito desde os 16 anos. Morava com a mãe, três irmãos e um sobrinho (um outro sobrinho nasceu durante o acompanhamento).

Os atendimentos foram realizados em um hospital universitário público do interior do Estado de São Paulo, referência em atendimento de alta complexidade quanto à saúde materno-infantil. O hospital oferece pré-natal especializado para gestantes portadoras de diversas patologias, como o diabetes, por exemplo, e, por esse motivo, a paciente estudada era atendida nesse local.

O serviço de Psicologia oferece apoio psicológico às gestantes sob a forma de encaminhamento, de demanda espontânea ou através da triagem, das psicólogas, de casos que demonstrem maior gravidade. No caso de Elaine, o contato inicial se deu pelo encaminhamento da equipe enquanto a paciente se encontrava internada, visto tratar-se de uma paciente com histórico de difícil adesão ao tratamento de controle do diabetes.

Os atendimentos ocorriam quinzenalmente, coincidindo com as consultas de prénatal. No dia em que comparecia ao hospital, a paciente era avaliada por médicos especialistas das áreas de obstetrícia e endocrinopatia, para acompanhamento da evolução materno-fetal e controle glicêmico, respectivamente.

Como citado anteriormente, o primeiro atendimento ocorreu no leito hospitalar. Estabeleceu-se um contrato entre a terapeuta e a paciente de que as próximas sessões ocorreriam no ambulatório da instituição, no retorno de pré-natal. Tanto nesse caso quanto com as outras pacientes, não havia horário fixo para atendimento psicológico, que poderia ocorrer antes ou após a consulta médica. No acompanhamento específico de Elaine, por coincidência, todas as consultas psicológicas ambulatoriais eram realizadas antes da consulta médica.

A técnica de atendimento psicológico consistiu na psicoterapia breve de orientação psicanalítica. Esse tipo de técnica permite o enfrentamento de problemas de ordem 
emocional de uma maneira mais rápida, já que paciente e terapeuta procuram soluções para uma situação de crise, que pode ser luto, gravidez, doenças ou cirurgias (Knobel, 1986).

Nesses momentos de crise, mesmo exposto ao perigo, o indivíduo conta com maior motivação para mudar, e, por essa razão, tende a aceitar uma intervenção terapêutica (Gebara, Rosa, Simon, \& Yamamoto, 2004). Embasado na teoria psicanalítica, o terapeuta busca a resolução dos conflitos inconscientes do paciente, com possíveis repercussões sobre o sujeito como um todo (Lowenkron, 2000).

A escolha pelo estudo de caso ocorreu por este se destacar como um valioso recurso tanto para a execução de pesquisas científicas como para o desenvolvimento de práticas em Psicologia - sejam elas clínicas, organizacionais, educacionais ou de qualquer outra ordem (Peres \& Santos, 2005).

A utilização dos conteúdos das sessões para a elaboração deste trabalho se deu após a aprovação da paciente e da assinatura do Termo de Consentimento Livre e Esclarecido.

\section{Resultados}

\section{Relato das sessões}

No primeiro atendimento psicológico, a paciente relatou que a gravidez não fora planejada. Houve tentativa de aborto, sem sucesso, e desde então esforçava-se para aceitar a gravidez. O atendimento inicial foi realizado no leito, visto que a paciente se encontrava internada. Foram investigadas questões referentes à patologia (há quanto tempo tinha o diagnóstico de diabetes, como foi diagnosticado, se realizava o tratamento adequadamente etc), bem como suas relações familiares e conjugais. Por vezes, Elaine se emocionou durante o atendimento e, ao final, agradeceu bastante.
Elaine residia com a mãe, três irmãos e dois sobrinhos. A irmã mais velha, de 22 anos, era a mãe das crianças e não trabalhava. $\mathrm{O}$ irmão de 18 anos também não trabalhava, e, segundo a paciente, era usuário de drogas; o irmão caçula tinha 9 anos.

Sobre o pai do bebê, afirmou que havia começado o relacionamento com ele na tentativa de esquecer o ex-namorado, com quem havia se relacionado por 2 anos e 5 meses. Durante o relacionamento, descobriu que ele já tinha outra namorada, que alguns meses depois ficou grávida e foi morar com o rapaz. Nesse período, a paciente se mudou da casa da mãe e foi morar sozinha, mantendo o relacionamento com o namorado que, a essa altura, já morava com a outra garota. Como o namorado a visitava raramente, a situação de ser sua amante foi ficando insustentável até que a paciente decidiu romper a relação. Pouco tempo depois, começou a se relacionar com o pai do bebê, apesar de ainda gostar do namorado anterior.

No segundo atendimento, realizado na consulta de pré-natal, foram aprofundadas questões como a relação com o ex-namorado, com o namorado atual e a dificuldade em aceitar a gravidez. Elaine parecia bastante receptiva, como se tivesse encontrado no atendimento psicológico um espaço onde pudesse se mostrar sem receio de ser julgada. Afirmou não gostar do pai do bebê, com quem ainda mantinha um relacionamento. Disse que "voltaria correndo" caso o exnamorado ainda a quisesse, pois havia se arrependido de ter posto fim ao namoro, apesar de todo o sofrimento que este lhe havia causado.

Também disse que pretendia sair da casa da mãe e morar sozinha após o nascimento do bebê, decisão, segundo ela, tomada em razão do atendimento realizado na data de sua internação. Cabe destacar que, no primeiro atendimento, foi questionado o 
motivo pelo qual Elaine aceitava arcar sozinha com a responsabilidade da família, visto que sustentava com seu salário a mãe, os três irmãos e o sobrinho, sendo dois irmãos adultos. Quando indagada sobre esse fato na primeira sessão, Elaine não soube responder, e, na segunda, disse ter o "coração mole". Exemplificou dizendo que a irmã inclusive frequentemente a agredia fisicamente, sem ela nunca ter revidado, mas que agora ia aprender a se impor e a pensar mais em si mesma.

No terceiro atendimento, Elaine falou um pouco mais sobre as relações familiares. Nunca havia tido uma boa relação com a mãe. Segundo a paciente, sua mãe não se comportava como tal, principalmente após a separação, quando passou a frequentar bailes e a se relacionar com homens muito mais jovens. A mãe de Elaine chegou a ficar com um ex-namorado dela, fato que a havia magoado muito. A relação com o pai também sempre havia sido muito conflituosa, pois ele sempre havia bebido muito e, nesses momentos, agredia a mãe, motivo pelo qual se separaram, seis anos atrás. Elaine disse que o pai nunca havia gostado dela e do irmão mais velho, frase dita pelo próprio pai. Quando indagada sobre a possível razão para essa hostilidade direcionada a ela e ao irmão, Elaine dizia não entender o porquê.

Na quarta sessão, Elaine chegou dizendo que o filho da irmã, que estava grávida pela segunda vez, havia nascido. Também disse que a mãe e o irmão tinham conseguido emprego e que o irmão inclusive não estava mais andando com a mesma turma, envolvida com drogas. Além de todas essas notícias, Elaine havia rompido o relacionamento com o namorado, pois havia decidido que "não queria ficar com ninguém só porque estava grávida", já que "sabia que não gostava dele". Trabalhamos os sentimentos referentes a essas mudanças e, em um dado momento da sessão, Elaine disse que "se via como uma caixa, e que estava abrindo a caixa".
No dia em que haveria o quinto atendimento psicológico, não foi possível atender a paciente antes da consulta médica, como o que já havia ocorrido nas outras vezes. Porém, após ser atendida pelo médico, não aguardou o atendimento psicológico. Nesse dia, seria avisado à paciente que, na próxima semana, a psicóloga entraria em período de férias, o que não pôde ser comunicado visto que Elaine não esperou pela consulta.

Passado pouco mais de um mês dessa data, a psicóloga, que havia retomado suas atividades, chamou Elaine para o atendimento que sempre ocorria em seu retorno de prénatal. Quando foi chamada, disse que não queria atendimento. Mesmo após essa primeira recusa, a paciente foi encaminhada à sala e, quando indagada sobre a razão de tal recusa, disse não haver motivo, mas que simplesmente "não estava com vontade de falar hoje". Após ter explicado o motivo de sua ausência (no período de férias), a psicóloga liberou a paciente.

No retorno de pré-natal seguinte, a paciente foi encaminhada à sala de atendimento psicológico e foi-lhe pedido que expusesse seus sentimentos em relação ao andamento da psicoterapia. Elaine afirmou que "não precisava mais de atendimento", porque, segundo ela, "as coisas haviam melhorado". Foram trabalhadas questões relativas a essa decisão, e a psicóloga encerrou o atendimento colocando-se à disposição.

\section{Discussão}

Analisando os atendimentos realizados, podemos observar que o atendimento psicológico representou para a paciente, ao menos inicialmente, uma possibilidade de experiência nova, na qual poderia sentir-se vista, valorizada e acolhida em suas angústias; dizemos experiência nova porque a história de vida de Elaine demonstra que suas relações (tantos parentais quanto pessoais) não the 
permitiram um espaço de troca e de respeito adequados.

Entretanto, alguns traços de personalidade comuns do diabético dizem respeito à oralidade, à dependência, à busca de atenção materna e à passividade excessiva (Sadock \& Sadock, 2007), traços que podem ser verificados pela expressão de emoção e gratidão da paciente durante as primeiras sessões, a ponto de, já no segundo atendimento, decidir morar sozinha após o nascimento do bebê, decisão ocorrida depois de alguns apontamentos feitos no primeiro atendimento psicológico.

Segundo Obstfeld, "o diabético se comporta, em seu distúrbio metabólico, como alguém que, vítima de uma forma particular de melancolia, dissipa, esbanja o que mais necessita negando e representando um ato de submissão inconsciente" (1997, p. 124).

Segundo Obstfeld, "o diabético se comporta, em seu distúrbio metabólico, como alguém que, vítima de uma forma particular de melancolia, dissipa, esbanja o que mais necessita negando e representando um ato de submissão inconsciente" (1997, p. 124).
O autor afirma que, durante o processo terapêutico, os diabéticos demonstram uma submissão que causa incômodo ao terapeuta, pois este sente que, apesar de elogiarem frequentemente suas interpretações, nunca ficam satisfeitos com elas. Isso ocorre porque o ódio proveniente da insatisfação que o paciente reprime leva-o a uma tentativa de apaziguar o terapeuta através de elogios que causam enjoo.

O quarto atendimento ilustra bem todo esse mecanismo de sedução que a paciente demonstrava transferencialmente. Como relatado anteriormente, nessa sessão, Elaine disse que a mãe e o irmão haviam conseguido trabalho, que havia terminado seu namoro sem amor e que o atendimento psicológico estava Ihe proporcionando uma possibilidade de desabrochar para a vida, ou seja, Elaine pretendia inconscientemente mostrar o quanto tinha amadurecido, amadurecimento ilusório, é preciso salientar, e tudo isso graças à ação da terapeuta.
Outra observação importante com relação ao modo de funcionamento mental do diabético refere-se à sobreproteção aos seres do seu convívio, consequência de uma projeção, no outro, do necessitado, do pobre, do miserável, enquanto o sujeito se pseudoidentifica com o objeto rico e recordado (Obstfeld, 1997).

Aqui cabem dois comentários. No que diz respeito à sobreproteção, observamos, no caso de Elaine, um exemplo evidente desse tipo de comportamento. A paciente se sacrificava pela família, sustentava a todos com seu salário sem receber, segundo ela, nenhum reconhecimento, chegando por vezes a ser agredida fisicamente pela irmã sem ter revidado, ou seja, projetava no outro a imagem do necessitado. Os comportamentos citados vão ao encontro das ideias de Obstfeld (1997), quando afirma que essa sobreproteção é demonstrada sob a forma de atos de sacrifício e culpa que, na realidade, escondem uma hostilidade reprimida.

Com relação ao mecanismo de pseudoidentificação, podemos refletir a respeito da função do trabalho de doméstica na vida de Elaine. É claro que não devemos deixar de lado a questão social e educacional envolvida na escolha dessa profissão, já que a paciente possuía baixa escolaridade (não concluiu o ensino médio) e, por esse motivo, restavam-lhe poucas possibilidades de escolha por outro tipo de trabalho. Entretanto, é sabido que, na profissão de doméstica, a paciente convivia com pessoas de nível social e educacional superior ao seu, o que poderia favorecer uma pseudoidentificação com o objeto rico (Obstfeld, 1997), entendendo-se rico no sentido geral do termo.

Fatores como a hereditariedade e a história familiar são importantes na eclosão do diabetes; todavia, sentimentos como frustração, solidão e desânimo, produtos de um stress emocional, podem desencadeá- 
la. Além disso, quando deprimido ou desanimado, o diabético pode comer ou beber excessiva e autodestrutivamente, em especial os pacientes com diabetes juvenil ou do tipo 1 (Sadock \& Sadock, 2007). Lembramos que o diagnóstico de diabetes da paciente estudada se deu quando esta contava 16 anos de idade, e que o encaminhamento ao serviço de Psicologia ocorreu pelo fato de Elaine apresentar histórico de baixa adesão ao tratamento, dados que corroboram os apontamentos citados acima.

Em conformidade com essa argumentação, Debray (1995) afirma que o funcionamento mental adequado do paciente permite um enfrentamento melhor da doença, enquanto um funcionamento mental perturbado pode desencadear complicações precoces decorrentes desse desequilíbrio.

Podemos marcar da primeira à quarta sessão como uma primeira fase, um momento em que a paciente, ao sentir-se acolhida, entregou-se na relação terapêutica e, ao mesmo tempo, temendo perder esse afeto, reagiu transferencialmente como se tivesse que corresponder de alguma forma e oferecer à terapeuta o que acreditava que esta gostaria de receber. Todos os conflitos trabalhados ao longo das sessões pareceram ter se resolvido rapidamente, reflexo da tentativa da paciente de seduzir a terapeuta, colocando-a como a responsável por tamanho crescimento.

Entretanto, ocorre uma ruptura brusca desse processo transferencial, quando a paciente vai embora sem esperar pelo atendimento psicológico e em seguida o recusa explicitamente.

Lembramos que essa recusa ocorreu após o período de férias da terapeuta, período em que a paciente continuou frequentando o hospital para a consulta de pré-natal sem saber (e também sem procurar se informar) a razão de não estar recebendo atendimento psicológico. Outro dado importante a se acrescentar diz respeito ao comportamento de Elaine frente à terapeuta no momento da recusa. Quando chamada para atendimento, a paciente, que conversava com uma colega na sala de espera, levantou-se e imediatamente disse que "não queria falar hoje". Enquanto caminhava em direção à terapeuta, demonstrava um certo sorriso e olhar irônicos, que se mantiveram na sala de atendimento. Após a tentativa frustrada por parte da terapeuta em compreender o motivo da recusa, Elaine foi liberada e retornou à sala em que aguardava por atendimento médico. Nos momentos em que a terapeuta passava pelo corredor da sala, a paciente, com o mesmo sorriso e olhar irônicos, parecia aumentar o tom da voz enquanto conversava com a colega ao lado.

Esse comportamento de Elaine vai ao encontro das ideias de Obstfeld (1997), que afirma que reações egoístas e mesquinhas, assim como a fanfarrice, configuram traços de caráter do diabético, sendo que essas reações na realidade atuam como defesas que escondem o sentimento de miséria interior.

Definimos as duas sessões (tanto a não esperada quanto a recusada) como uma segunda fase do processo terapêutico. Reforçando o que já foi discutido anteriormente, em um primeiro momento, a paciente reagiu como se tivesse encontrado na terapeuta um oásis, alguém com quem pudesse usufruir de uma plenitude inesgotável, reação transferencial típica do diabético (Obstfeld, 1997).

Entretanto, Obstfeld (1997) também caracteriza os diabéticos como pessoas com necessidades exageradas de afeto que, por serem exageradas, nunca são satisfeitas. Em consequência do afeto não satisfeito, surgem sentimentos de frustração que se traduzem em reações de hostilidade. 
Foi o que verificamos nessa segunda fase do processo terapêutico. A paciente, dotada de um traço de caráter demasiadamente dependente de afeto, se depara com um dado concreto gerador de um sentimento de frustração - o abandono - causado pela terapeuta (devido às férias). Dessa forma, a terapeuta, que até então ocupava o lugar de objeto bom e acolhedor, de repente é vista como um objeto mau, frustrador, o que é refletido na reação de hostilidade por parte da paciente.

Obstfeld (1997) faz um paralelo entre a sociedade de consumo e o caráter diabético. Segundo esse autor, um componente importante da sociedade de consumo é a insatisfação do homem e a dificuldade para gozar o que adquire, levando-o a adquirir cada vez mais objetos, em uma busca ilusória de bem-estar. A aquisição desenfreada de objetos revela uma conduta maníaca que encobre uma situação melancólica caracterizada por um sentimento de perda e de insatisfação permanentes.

Para Obstfeld (1997), esse mecanismo produz um círculo vicioso que tende a ser substituído rápida e continuamente, em uma atitude de esbanjamento que está a serviço da busca ilusória de um gozo inatingível.

Foi o que verificamos no atendimento psicológico, em que a paciente repetiu o mesmo mecanismo de esbanjamento e substituição de um objeto (no caso, a terapeuta) que não lhe servia mais.

\section{Considerações finais}

A partir dos atendimentos psicológicos realizados, pôde-se constatar alguns mecanismos típicos do diabético, que se revelaram tanto através das observações do modo de funcionamento nas relações da paciente quanto de sua relação transferencial com a psicóloga.
Alguns dos mecanismos expostos neste trabalho, quando detectados no processo terapêutico, não puderam ser trabalhados entre paciente e terapeuta, pois, como demonstrado neste artigo, houve uma ruptura brusca do atendimento psicológico, que não pôde ser restabelecido.

Outros fatores podem também ter prejudicado o andamento da relação terapêutica, como as dificuldades da paciente em lidar com seus conflitos, a contratransferência por parte da terapeuta e mesmo a influência do funcionamento institucional.

Sobre a contratransferência, é possível que a psicóloga tenha se envolvido com a situação de sofrimento da paciente a ponto de alimentá-la em suas fantasias inconscientes; quando frustrada, Elaine abdicou da parceria.

Entretanto, é importante salientar que não houve procura por atendimento psicológico, visto que a paciente frequentava o hospital para o acompanhamento de pré-natal; o atendimento foi oferecido pela psicóloga. Além disso, fatos externos à situação terapêutica (como o período de férias da psicóloga) somaram-se a questões internas da paciente, o que culminou com a ruptura do vínculo.

Dessa forma, apesar das dificuldades enfrentadas ao longo do processo terapêutico, acreditamos que este trabalho possa servir para ilustrar as vivências de um atendimento psicológico dentro de uma instituição hospitalar, salientando o mérito da paciente, que prosseguiu até onde suas defesas lhe permitiram. 


\section{Roselaine Fernanda Barbosa}

Aprimoramento/Especialização em Psicologia Hospitalar e Saúde Reprodutiva Mulher,

CAISM - UNICAMP. Psicóloga da Prefeitura Municipal de Campo Limpo Paulista, São Paulo - SP - Brasil.

E-mail: roselainefb@yahoo.com.br

\section{Cláudia Aparecida Marchetti Duarte}

Mestrado em Tocoginecologia pela Universidade Estadual de Campinas-UNICAMP.

Professora de Atividade prática da Faculdade de Jaguariúna -FAJ

Psicóloga do Setor de Adolescente Prefeitura de Valinhos - São Paulo, SP - Brasil.

E-mail: clauamduarte@yahoo.com.br

\section{Laise Potério dos Santos}

Mestrado em Tocoginecologia pela Universidade Estadual de Campinas-UNICAMP

Psicóloga da área de Obstetrícia "Hospital da Mulher Prof Dr José Aristodemo Pinotti"- CAISM - UNICAMP.

Supervisora da Seção de Psicologia do CAISM - UNICAMP, São Paulo - SP - Brasil.

Email: lapoterio@gmail.com, psicologia@caism.unicamp.br

Endereço para envio de correspondência:

Rua Diamantina, 252 Jardim Imperial, Atibaia - São Paulo - SP - Brasil. CEP: 12970-070

Recebido 25/1/2010, 1a Reformulação 5/12/2011, Aprovado 10/1/2012.

\section{Referências}

Aquino, M. M. A., Pereira, B. G., Amaral, E., Parpinelli, M. A., \& Passini Jr., R. (2003). Revendo diabetes e gravidez. Revista de Ciências Médicas, 12(1), 99-106.

Angerami-Camon, V. (Org.). (2003). A psicologia no hospital (2a. ed.). São Paulo: Thomson - Pioneira.

Bortoletti, F. F. (2007). Psicodinâmica do ciclo gravídico puerperal. In F. F. Bortoletti, A. F. Moron, J. Bortoletti Filho, M. U. Nakamura, R. M. Santana \& R. Mattar (Orgs.), Psicologia na prática obstétrica: abordagem interdisciplinar (pp. 22-36). Barueri, SP: Manole.

Canavarro, M. C. (2001). Gravidez e maternidade - representações e tarefas de desenvolvimento. In M. C. Canavarro (Ed.), Psicologia da gravidez e da maternidade (pp.17-49). Coimbra, Portugal: Quarteto Editora.

Capitão, C. G., \& Carvalho, E. B. (2006). Psicossomática: duas abordagens de um mesmo problema. PSIC - Revista de Psicologia da Vetor Editora, 7(2), 21-29.

Chiozza, L. A. (1987). Por que adoecemos? A história que se oculta no corpo (M. J. D. R. S. Peres, trad.). Campinas: Papirus.

Coelho, C. L. S., \& Ávila, L. A. (2007). Controvérsias sobre a somatização. Revista Psicologia Clínica, 34(6), 278-284.

Corrêa, F. H. S., \& Gomes, M. B. (2004). Acompanhamento ambulatorial de gestantes com diabetes mellitus no Hospital Universitário Pedro Ernesto - UERJ. Arquivos Brasileiros de Endocrinologia \& Metabologia, 48(4), 499-504.

Debray, R. (1995). O equilíbrio psicossomático: um estudo sobre diabéticos (J. Werneck, trad.). São Paulo: Casa do Psicólogo.

Ferraz, F. C. (2007). A tortuosa trajetória do corpo na psicanálise. Revista Brasileira de Psicanálise, 41(4), 66-76.

Fossi, L. B., \& Guareschi, N. M. F. (2004). A psicologia hospitalar e as equipes multidisciplinares. Revista da Sociedade Brasileira de Psicologia Hospitalar, 7(1), 29-43.

Gebara, A. C., Rosa, J. T., Simon, R., \& Yamamoto, K. (2004). Eficácia terapêutica da interpretação teorizada na psicoterapia breve. Revista de Psicologia da Vetor Editora, 5(1), 6-15.

Golbert, A., \& Campos, M. A. A. (2008). Diabetes melito tipo 1 e gestação. Arquivos Brasileiros de Endocrinologia \& Metabologia, 52(2), 307-314.

Gross, J. L., Silveiro, S. P., Camargo, J. L., Reichelt, A. J., \& Azevedo, M. J. (2002). Diabetes melito: diagnóstico, classificação e avaliação do controle glicêmico. Arquivos Brasileiros de Endocrinologia \& Metabologia, 46(1), 16-26.

Horn, A. (2007). O somático e as experiências corporais. Revista Brasileira de Psicanálise, 41(1), 102-107.
Knobel, M. (1986). Psicoterapia breve (2a. ed.). São Paulo: EPU.

Lowenkron, T. S. (2000). É possível psicanálise breve? Revista Latinoamericana de Psicopatologia Fundamental, 3(4), 59-79.

Maldonado, M. T. P. (2002). Psicologia da gravidez: parto e puerpério (16a ed.). São Paulo: Saraiva.

Mello, J. de, Filho. (1994). Concepção psicossomática: visão atual (7a ed.). Rio de Janeiro: Tempo Brasileiro.

Montenegro Jr., R. M., Paccola, G. M. F. G., Faria, C. M., Sales, A. P. M., Montenegro, A. P. D. R., Jorge, S. M. et al. (2001). Evolução materno-fetal de gestantes diabéticas seguidas no HC-FMRP-USP no período de 1992-1999. Arquivos Brasileiros de Endocrinologia \& Metabologia, 45(5), 467-474.

Moretto, M. L. T. (2001). O que pode um analista no hospital? São Paulo: Casa do Psicólogo.

Obstfeld E. (1997). Psicanálise do distúrbio diabético. In L. A. Chiozza (Org.), Os afetos ocultos em: psoríase, asma, transtornos respiratórios, varizes, diabetes, transtornos ósseos, cefaléias e acidentes cerebrovasculares (L. Y. de Massuh, trad., pp. 115-143). São Paulo: Casa do Psicólogo.

Peres, R. S., \& Santos, M. A. dos. (2005). Considerações gerais e orientações práticas acerca do emprego de estudos de caso na pesquisa científica em psicologia. Interações, 10(20), 109-126.

Sadock, B. J., \& Sadock, V. A. (2007). Compêndio de psiquiatria: ciências do comportamento e psiquiatria clínica (9a ed., C. Dorneles et al., trads.). Porto Alegre: Artmed.

Santos, L. P. dos. (2003). Ansiedade e depressão associadas ao diagnóstico do diabetes mellitus gestacional. Dissertação de mestrado. Faculdade de Ciências Médicas, Universidade Estadual de Campinas, Campinas, SP.

Sebastiani, R. W. (2007). Psicologia da saúde: uma especialidade dedicada ao cuidado humano. In F. F. Bortoletti, A. F. Moron, J. Bortoletti Filho, M. U. Nakamura, R. M. Santana \& R. Mattar (Orgs.), Psicologia na prática obstétrica: abordagem interdisciplinar (pp.1-13). Barueri, SP: Manole.

Silva, L., Santos, R. C., \& Parada, C. M. G. L. (2004). Compreendendo o significado da gestação para grávidas diabéticas. Revista Latino-americana de Enfermagem, 12(6), 899-904.

Simonetti, A. (2004). Manual de psicologia hospitalar: o mapa da doença. São Paulo: Casa do Psicólogo.

Winnicott, D. W. (1982). Textos selecionados: da pediatria à psicanálise (2a ed., J. Russo, trad.). Rio de Janeiro: Francisco Alves.

Zeljko, L. (2000). O animal humano. Natureza Humana, 2(2), 351-397. 